Article

\title{
Synthesis and Investigation of Thermal Properties of Highly Pure Carboxylic Fatty Esters to Be Used as PCM
}

\author{
Rebecca Ravotti, Oliver Fellmann, Nicolas Lardon, Ludger J. Fischer, Anastasia Stamatiou * and \\ Jörg Worlitschek
}

Competence Centre Thermal Energy Storage (TES), Lucerne University of Applied Sciences and Arts, 6048 Horw, Switzerland; rebecca.ravotti@hslu.ch (R.R.); oliver.fellmann@hslu.ch (O.F.); nicolas.lardon@hslu.ch (N.L.); ludger.fischer@hslu.ch (L.J.F.); joerg.worlitschek@hslu.ch (J.W.)

* Correspondence: anastasia.stamatiou@hslu.ch; Tel.: +41-(0)41-349-3297

Received: 30 May 2018; Accepted: 27 June 2018; Published: 30 June 2018

\begin{abstract}
Latent heat storage systems are gaining the attention of researchers as possible substitutes to conventional sensible heat storage systems due to their compactness and their ability to absorb and release heat almost isothermally. Among the Phase Change Materials (PCM) for energy storage studied so far, esters are believed to show promising properties. In particular, a broad range of melting temperatures, little to no supercooling, low corrosivity, chemical and thermal stability, and high enthalpies of fusion are reported. Many esters have the advantage of being bio-based and biodegradable, making them more sustainable in comparison to other popular PCM. Still, a clear lack of experimental data exists in regards to this class. In the present study, esters derived from saturated fatty carboxylic acids (myristic, palmitic, stearic, behenic), coupled with primary linear alcohols of different length (methanol, 1-decanol) were synthesized through Fischer esterification and their properties were investigated. Purities higher than $89 \%$ were obtained for all cases as proven by gas chromatography coupled with mass spectroscopy and nuclear magnetic resonance analysis. Additionally, the esters' formation and reaction kinetics were characterized by attenuated total reflectance infrared spectroscopy. The esters produced showed to possess relatively high enthalpies of fusion above $190 \mathrm{~J} / \mathrm{g}$ and thermal stability over three repeated cycles with differential scanning calorimetry. The melting points measured ranged between $20^{\circ} \mathrm{C}$ and $50{ }^{\circ} \mathrm{C}$, therefore proving to be interesting candidates for low-medium temperature applications such as heating and cooling in buildings. A correlation could be observed between the chemical structure and melting point of the produced esters. Additionally, thermogravimetric analysis revealed a higher thermal resistance for esters with longer aliphatic chains in comparison to shorter-chained ones.
\end{abstract}

Keywords: latent heat storage; phase change material; esters; thermal energy storage; fatty esters; decyl esters; methyl esters

\section{Introduction}

The recent trends in energy consumption and energy policies are shifting the focus to sustainable utilization of energy as a key issue [1,2]. Based on an International Energy Agency (IEA) report [1], a steep increase in global primary energy consumption has been observed over the last few years. Roughly $50 \%$ of this energy is being used to heat and cool applications in the industrial and domestic sectors. Thermal Energy Storage (TES) systems are arising as key technologies to help increase energetic efficiency and enable a high share of renewable energies for future energy systems [1-3]. TES can be divided into three main categories: Sensible Heat Storage (SHS), Latent Heat Storage (LHS) and 
Thermo-Chemical Heat Storage (TCS). In LHS systems, heat is stored in the form of phase change enthalpy, which can be accumulated or released upon phase change of the energy-storing material $[2,3]$. As such, this application requires materials with high phase change enthalpies, which are referred to as Phase Change Materials (PCM). As reported by Sharma et al. (2009) [4], due to higher compactness and higher heat storage density, LHSs allow for greater flexibility in the location selection of the storage system and minimum space usage. PCMs accumulate energy while the phase change occurs at almost isothermal conditions and over narrower temperature ranges, therefore providing higher energy efficiency with a smaller temperature difference between charging and discharging in comparison to sensible storage [5-7]. However, in addition to higher investment costs compared to SHSs, PCMs often face issues with toxicity, flammability, and possible degradation of properties after several cycles [5].

Early studies focused on salt hydrates as inorganic PCMs due to their availability, low cost, and high latent heat storage capacities. However, because of their tendency to corrode, supercool and segregate, researchers have turned their attention towards organic PCMs as well [8-10]. Paraffins are the most commonly used organic PCMs as of today; however, they are oil derivatives and are characterized by high flammability and relatively limited melting point range. Therefore, carboxylic acids and their derivatives have been selected as a more sustainable alternative [10-12]. In particular, in order to reduce environmental impact, research is being conducted on organic PCMs based on readily available natural resources, such as carboxylic esters, which naturally occur in fats and oils from renewable feedstock [10-12]. Menoufli et al. [11] conducted preliminary studies on the environmental impact of salt hydrates and esters as PCM in house-shaped cubicles in Spain. The results showed that based on the Eco-indicator 99 method, an impact reduction of 10.5\% for esters compared to paraffins was calculated. Carboxylic esters can be obtained via Fischer esterification of carboxylic acids with alcohols, and present comparable thermal and chemical characteristics to the original acids [12]. In fact, similarly to the corresponding carboxylic acids, they are reported to show low or no toxicity, no corrosivity, high enthalpies of fusion, high chemical and thermal stability, and are mainly inflammable [8,9]. Millions of possible combinations between carboxylic acids and alcohols exist, creating endless possibilities for esters as PCMs [8]. However, despite the advantages reported above, esters as PCM have not been investigated deeply so far. As reported by Stamatiou [12] and Aydin $[13,14]$, a clear gap in the data concerning experimental thermal properties of esters derived from carboxylic esters exists. This is probably due to lack of easily available commercial products, which makes it challenging to collect experimental data.

In order to allow for identification of potential esters to be used as future PCM in relevant temperature ranges, more experimental data on the thermal properties of esters is required. The interpretation of these data could also help gain a clearer understanding of the dependence between chemical structure and thermal properties. While little experimental data on enthalpies of fusion exists, previous studies on the correlation between molecular structure and melting temperature have been performed. Firstly, Carnelley [15] in 1882, and more recently Boese et al. [16] in 2001 both observed that symmetrical molecules with efficient crystal packing tend to have higher melting points due to stronger intermolecular bonding. This is true for molecules with higher molecular weights because of lower kinetic energy and therefore more tightly packed structures. For the same reason, branched molecules are reported to have lower melting points compared to linear homologues since they tend to form less packed structures [16]. As reported by Noël et al. [17] and Yang et al. [18], the melting points of alkanes increase with longer carbon chains, with two different trends for even and odd numbered carbon chains, where even-numbered ones present higher values. Stamatiou et al. [12] examined 11 commercially available linear fatty esters for use as PCM, and confirmed the trends reported above for melting points in relation to molar mass. Other studies have been performed on the subject. Aydin et al. $[13,14]$ synthesized even-numbered fatty acid esters of myristyl alcohol and esters from dicarboxylic acids with promising enthalpies of fusion over $200 \mathrm{~J} / \mathrm{g}$. Sari et al. [19] synthesized esters derived from stearic acid with glycerol, isopropyl alcohol and n-butyl alcohol through Fischer esterification. 
In this study, synthesis of linear fatty esters from fatty acids of different even-numbered chain lengths (Myristic Acid MY $\left(C_{14}\right)$, Palmitic Acid PA $\left(C_{16}\right)$, Stearic Acid SA $\left(C_{18}\right)$, Behenic Acid BE $\left(C_{22}\right)$ ), coupled with alcohols (methanol $\left(C_{1}\right)$ and 1-decanol $\left(C_{10}\right)$ ) was performed. All IUPAC names, trivial names, chemical structures and shortenings from the esters produced are reported in Figure A1. The thermal properties of the esters produced were analyzed to individuate possible trends with the molecular structure, and to obtain a broader overview on the possible range of melting points. In order to optimize and validate the synthesis, at first a commercially available ester (Methyl Palmitate) was reproduced in the laboratory and the resulting properties compared with the one purchased by manufacturers. Following optimization of the synthesis procedure, new esters of fatty acids with methanol (MeOH) and 1-decanol was produced. Methyl Palmitate (MEPA), Methyl Myristate (MEMY) and Methyl Stearate (MESA) have been previously produced and are available at affordable prices, while Methyl Behenate (MEBE) is also available at higher prices. Little to no thermal data has been found on fatty esters derived from 1-Decanol, and their commercial availability is limited.

\section{Materials and Methods}

Carboxylic PA ( $\geq 90 \%$ ) was purchased from Vopak (Rotterdam, Netherlands), MY ( $\geq 99 \%)$ from Sigma Aldrich (Saint Louis, MO, USA), SA ( $\geq 90 \%$ ) from Alfa Aesar (Haverhill, MA, USA), BE ( $\geq 85 \%$ ) from Alfa Aesar (Haverhill, MA, USA), while alcohols $\mathrm{MeOH}$, and 1-decanol were acquired from Sigma Aldrich with high purities $(\geq 99 \%)$ as synthesis precursors. MEPA from Sigma Aldrich $(\geq 99 \%)$ was used as commercial reference for synthesis optimization. Concentrated sulfuric acid $\left(\mathrm{H}_{2} \mathrm{SO}_{4}\right)$ was used as the acid catalyst, Sodium Sulfate anhydrous $\left(\mathrm{Na}_{2} \mathrm{SO}_{4}\right)$ as a water-absorbing agent for elimination of water, diethyl ether $\left(\mathrm{Et}_{2} \mathrm{O}\right)$ and ethyl acetate $(\mathrm{EtOAc})$ as organic solvents for separation; they were all purchased from Sigma Aldrich with purities $\geq 99 \%$. All chemical materials were used without any prior purification.

\subsection{Synthesis Development}

\subsubsection{Synthesis Mechanism and Instrumentation}

The esters were synthesized based on Fischer esterification process with $\mathrm{H}_{2} \mathrm{SO}_{4}$ as a catalyst. Under acidic conditions, the oxygen from the carbonyl group is protonated, thus creating a partial positive charge on the carbon, which is more prone to be attacked by the nucleophilic alcohol. Water is then formed by proton transfer and eliminated. Upon deprotonation of the carbonyl oxygen, the double bond is formed again to create the resulting ester group. Since the reaction is an equilibrium based on Le-Châtelier principle, it can be shifted towards the products (ester) by working with an excess of alcohol under refluxing conditions [20]. The reaction mechanism is shown in Figure 1.

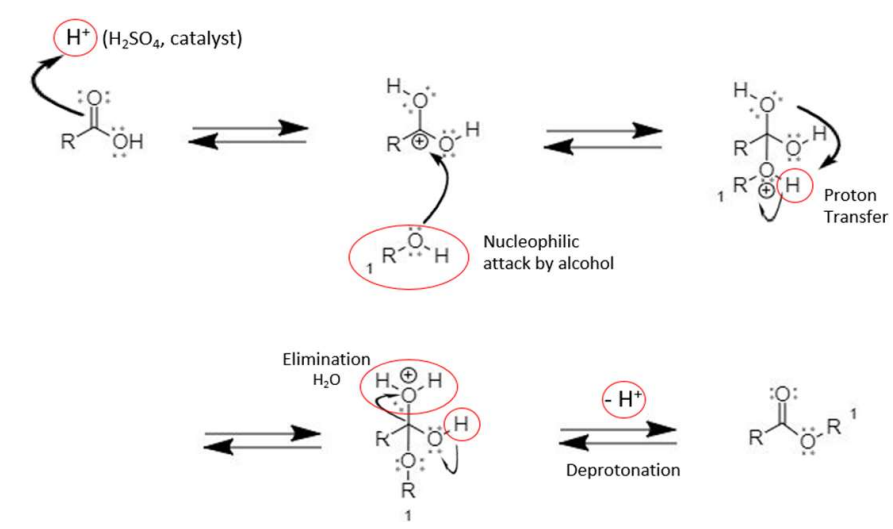

Figure 1. Reaction mechanism of Fischer esterification. Catalytic activation of the carboxylic group is needed to favor the nucleophilic attack from the alcohol. The red circles highlight the different attacking and leaving groups. 
The synthesis was performed in a two-necked round bottom flask with a magnetic stirrer and thermometer, equipped with a reflux condenser and immersed in an oil bath with a temperature-regulating sensor. In a $100 \mathrm{~mL}$ two-necked round bottom, the fatty acid $(0.02 \mathrm{moL})$ and alcohol $(0.1 \mathrm{moL}$, 5:1 alcohol:acid ratio) were added, and the oil bath was heated to $100{ }^{\circ} \mathrm{C}$ and the stirring set to $200 \mathrm{rpm}$. Upon complete melting of the acid, $1 \mathrm{~mL}$ of concentrated $\mathrm{H}_{2} \mathrm{SO}_{4}$ (concentrated at $95-98 \%$ ) was added to the reaction mixture. The reagents were left to react for $5 \mathrm{~h}$, after which the flask was allowed to cool down to room temperature. Afterwards, $\mathrm{Et}_{2} \mathrm{O}$ or EtOAc was added to the reaction mixture. The obtained solution was washed three times with deionized water, and the organic phase separated in a separating funnel. $\mathrm{Na}_{2} \mathrm{SO}_{4}$ (anhydrous) was then added to the organic phase to create an oversaturated solution in order to dry it from eventual residual water [20,21]. After $10 \mathrm{~min}$, the solution was filtered using filtering paper and the excess organic solvent removed in the rotary evaporator (Rotavapor Büchi RII) at $50^{\circ} \mathrm{C}$ bath temperature and $100 \mathrm{mbar}$ for approximately $1 \mathrm{~h}$. In order to ensure statistical relevance to the results obtained and to guarantee reproducibility, all synthesis described in the next chapters was repeated three times.

\subsubsection{Purification}

The esters produced were purified according to the degree of impurity observed in the Attenuated Total Reflectance Infrared Spectroscopy (ATR-IR) and Nuclear Magnetic Resonance (NMR). Esters derived from $\mathrm{MeOH}$ were not processed further following solvent removal with Rotavapor, since they presented degree of purity.

Conversely, those derived from 1-Decanol presented relevant traces of residual alcohol following drying in Rotavapor. Therefore, they were first dissolved in $\mathrm{MeOH}$ at ratio 10:1 alcohol:ester to favor the migration of residual 1-Decanol in the $\mathrm{MeOH}$ hydrophilic phase, then crystallized at $2-5^{\circ} \mathrm{C}$ overnight (1-Decanol melting point at $6{ }^{\circ} \mathrm{C}$ ), and afterwards filtered through vacuum filtration by washing with $\mathrm{MeOH}$.

Upon observation of the resulting products, if 1-decanol was still detected in ATR-IR or any other analytical technique, the crystallization procedure was repeated until disappearance of the impurities. Generally, purification by one crystallization process was sufficient for most esters, but in some cases, it had to be repeated up to three times.

\subsection{Characterization}

\subsubsection{Differential Scanning Calorimetry (DSC)}

Based on TA instruments application note [22], analysis of melting and crystallization temperatures was conducted via DSC $823^{\mathrm{e}}$ by METTLER TOLEDO between $-25{ }^{\circ} \mathrm{C}$ and $100{ }^{\circ} \mathrm{C}$ at $10^{\circ} \mathrm{C} / \mathrm{min}$ heating rates. The DSC was calibrated with indium standard before the measurements, and the uncertainty of the instrument was $\pm 0.1 \mathrm{~K}$. The samples were measured under a constant flow of nitrogen at a rate of $100 \mathrm{~mL} / \mathrm{min}$, and samples masses were between $5 \mathrm{mg}$ and $15 \mathrm{mg}$. In order to test the stability of the samples, the heating/cooling cycles were repeated three times with the same method for the same sample. Moreover, as stated previously, all syntheses were repeated three times to ensure reproducibility; therefore, each ester was measured three times, with three cycles per sample. All uncertainty values reported in the next pages are based on replicate measurements, therefore denoting the accuracy of the results. To evaluate the degree of supercooling, the difference between the onset melting peak and the onset crystallization peak reported from the instrument were considered.

\subsubsection{Thermal Gravimetric Analysis (TGA)}

The samples' thermal stability and degradation were analyzed by TGA on a STAR 2 System by METTLER TOLEDO in the temperature range between $25^{\circ} \mathrm{C}$ and $600{ }^{\circ} \mathrm{C}$ with a heating rate of $10^{\circ} \mathrm{C} / \mathrm{min}$ and sample masses between $15-20 \mathrm{mg}$. The uncertainty of the instrument's balance is 
reported to be $0.1 \mu \mathrm{g}$. For each sample, a blank measurement of the empty crucible was performed with the same method as described above for correct baseline subtraction.

\subsubsection{Attenuated Total Reflectance Infrared Spectroscopy (ATR-IR)}

In order to gain structural information on the samples produced, as well as the degree of purity and the kinetics of the reaction, ATR-IR Cary 630 by Agilent Technologies (Santa Clara, CA, USA) in the wavenumber range between 4000 and $600 \mathrm{~cm}^{-1}$ with $4 \mathrm{~cm}^{-1}$ resolution was used. No prior sample preparation was needed, and a background spectra was registered every 30 min with 32 scans. Afterwards, a few mg of the samples were simply deposited on the diamond tip in either solid or liquid form and the spectrum was registered with 32 scans.

\subsubsection{Gas Chromatography Coupled with Mass Spectroscopy (GC-MS)}

Gas chromatograms were measured on an Agilent Technologies GC 6890N connected to Agilent MSD 5973 with EI standard source, with Topaz $4.0 \mathrm{~mm}$ inlet liner with Wool in split mode 1:10 on a Supelco SLB-5 ms $30 \mathrm{~m} \times 250 \mu \mathrm{m} \times 0.25 \mu \mathrm{m}$ column and $1.3 \mathrm{~mL} / \mathrm{min}$ flow rate. The oven program was $100{ }^{\circ} \mathrm{C}$ for $1 \mathrm{~min}$, then $10^{\circ} \mathrm{C} / \mathrm{min}$ heating rate to $300{ }^{\circ} \mathrm{C}$ and at hold for 4 min afterwards. The temperature of the MSD transfer line was $250{ }^{\circ} \mathrm{C}$. Mass spectra were measured with electron ionization (EI) at $70 \mathrm{eV}$, source temperature of $200^{\circ} \mathrm{C}$, acceleration voltage of $5 \mathrm{kV}$, and resolution of 2500. The instrument was scanned between $m / z 100$ und 600 at scan rate of $2 \mathrm{~s} /$ decade in the magnetic scan mode. Perfluorokerosene (PFK, Fluorochem, Hadfield, Derbyshire, UK) served for calibration. The samples were diluted in chloroform with a concentration of $0.1 \mathrm{mg} / \mathrm{mL}$ and injection volume was $1 \mu \mathrm{L}$.

\subsubsection{Nuclear Magnetic Resonance (NMR)}

All ${ }^{1} \mathrm{H}$ NMR spectra were recorded using a Bruker (Billerica, MA, USA) $400 \mathrm{MHz}\left({ }^{1} \mathrm{H}\right)$ spectrometer at room temperature (unless otherwise stated). Chemical shifts ( $\delta$-values) are reported in ppm, spectra were calibrated relative to the residual proton chemical shifts $\left(\mathrm{CDCl}_{3}, \delta=7.26\right)$ of the solvent.

\section{Results and Discussion}

\subsection{Synthesis Development and Optimization}

In order to validate the suitability of the developed synthesis method, commercial MEPA was purchased and its main thermal properties were compared with those of the MEPA produced in the laboratory in-house. Based on the results obtained, the synthesis was adjusted accordingly to obtain the highest degree of purity and conversion possible. Once the synthesis was optimized, esters of methanol and 1-decanol were synthesized and studied.

\subsubsection{ATR-IR Analysis}

At first, the raw materials were analyzed on ATR-IR for correct assignment of the main peaks and structure identification. The characteristic ester peak from the stretching of $\mathrm{C}=\mathrm{O}$ group is observed at $1735 \mathrm{~cm}^{-1}$, while the stretching of $\mathrm{C}=\mathrm{O}$ from the carboxylic acid occurs at $1705 \mathrm{~cm}^{-1}$, which allows for identification of residual acid in the ester product. At $1150 \mathrm{~cm}^{-1}$, a sharp peak for $\mathrm{C}-\mathrm{O}-\mathrm{C}$ stretching from esters is visible, while it is completely absent in the acid spectra. The peaks at 2850 and $2920 \mathrm{~cm}^{-1}$ belong to the alkane chain, and the ratio between them and the ester peak at $1735 \mathrm{~cm}^{-1}$ can be seen increasing for increasing carbon chain length [23]. A characteristic broad peak from the stretching of $\mathrm{O}-\mathrm{H}$ in alcohols is observed between $3100-3600 \mathrm{~cm}^{-1}$. A shouldering broad peak from 2300 to $3000 \mathrm{~cm}^{-1}$ from the stretching of $\mathrm{O}-\mathrm{H}$ in carboxylic acids is observed in the spectra of PA, but as expected is completely absent in MEPA spectra, which allows for further observation of impurities in produced esters (Figure 2). 


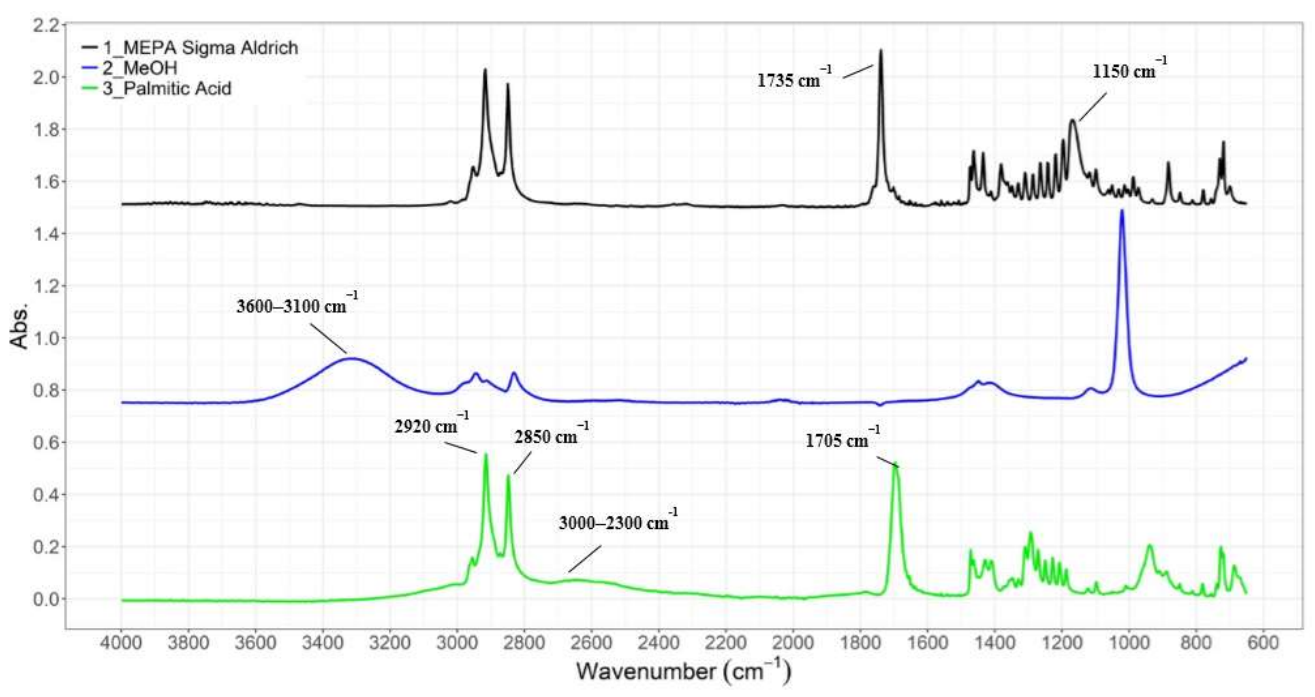

Figure 2. ATR-IR of commercial MEPA from Sigma Aldrich compared to raw materials PA and MeOH. The main peaks of interest for correct characterization of the esters produced and structure control are highlighted; in particular, the stretch of $\mathrm{C}=\mathrm{O}$ at 1705 and $1735 \mathrm{~cm}^{-1}$ for carboxylic acids and esters respectively, the broad peaks between $3600-3100 \mathrm{~cm}^{-1}$ and $3000-2300 \mathrm{~cm}^{-1}$ from $\mathrm{O}-\mathrm{H}$ stretch of alcohols and carboxylic acids, and finally the peak at $1150 \mathrm{~cm}^{-1}$ from $\mathrm{C}-\mathrm{O}-\mathrm{C}$ stretch in esters.

Following structural characterization of the raw materials, the synthesis was performed and the product compared with commercial MEPA. In order to investigate the effect of heating time and $\mathrm{COOH}: \mathrm{OH}$ ratio on the product formation, synthesis with increasing heating times and with two different ratios (COOH:OH 1:4 and 1:5) have been performed. As Figure 3 shows, slight improvements in the ester yield were observed when raising the $\mathrm{COOH}: \mathrm{OH}$ ratio from 1:4 to 1:5 excess. In fact, when comparing the absorbance of the ester peak $\left(1735 \mathrm{~cm}^{-1}\right)$ against the unreacted PA peak $\left(1705 \mathrm{~cm}^{-1}\right)$, a growth in the ester:acid ratio from 4.7 to 4.85 was observed for higher ratios $\mathrm{COOH}: \mathrm{OH}$ of 1:5. As a result, such excess of alcohol was considered optimal for ester formation and used for all further synthesis (Figure 3).

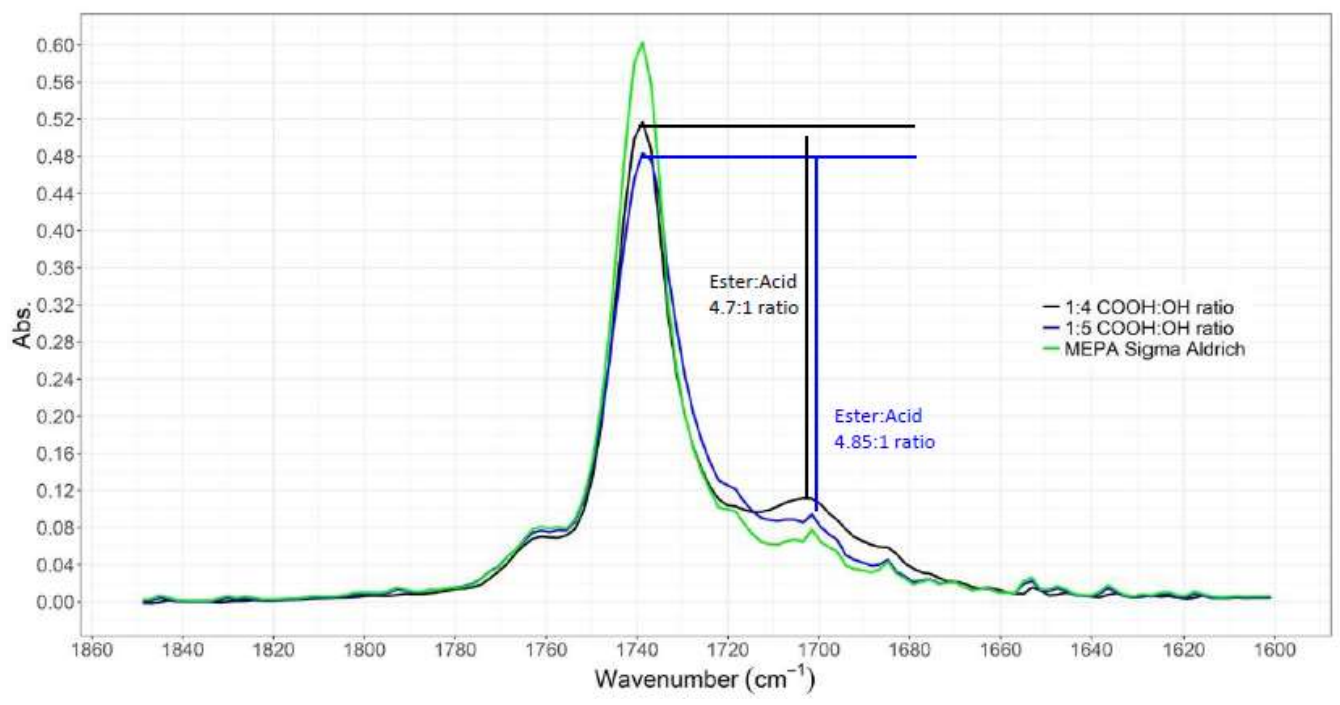

Figure 3. Investigation on the influence of $\mathrm{COOH}: \mathrm{OH}$ ratio on the ester formation. A gain in ester yield is observed for ratio of 1:5 COOH:OH compared to 1:4. 
Concerning the influence of heating time on the ester formation, as shown in Figure 4, the unreacted acid can be seen decreasing over increasing heating times, while conversely the ester peak is increased. No further change in the ester formation is observed following $5 \mathrm{~h}$ heating time, since the curve for $9 \mathrm{~h}$ and $45 \mathrm{~m}$ heating time equals the one from $5 \mathrm{~h}$ heating. Therefore, $5 \mathrm{~h}$ was considered as the end point of the reaction, and followed for all subsequent syntheses.

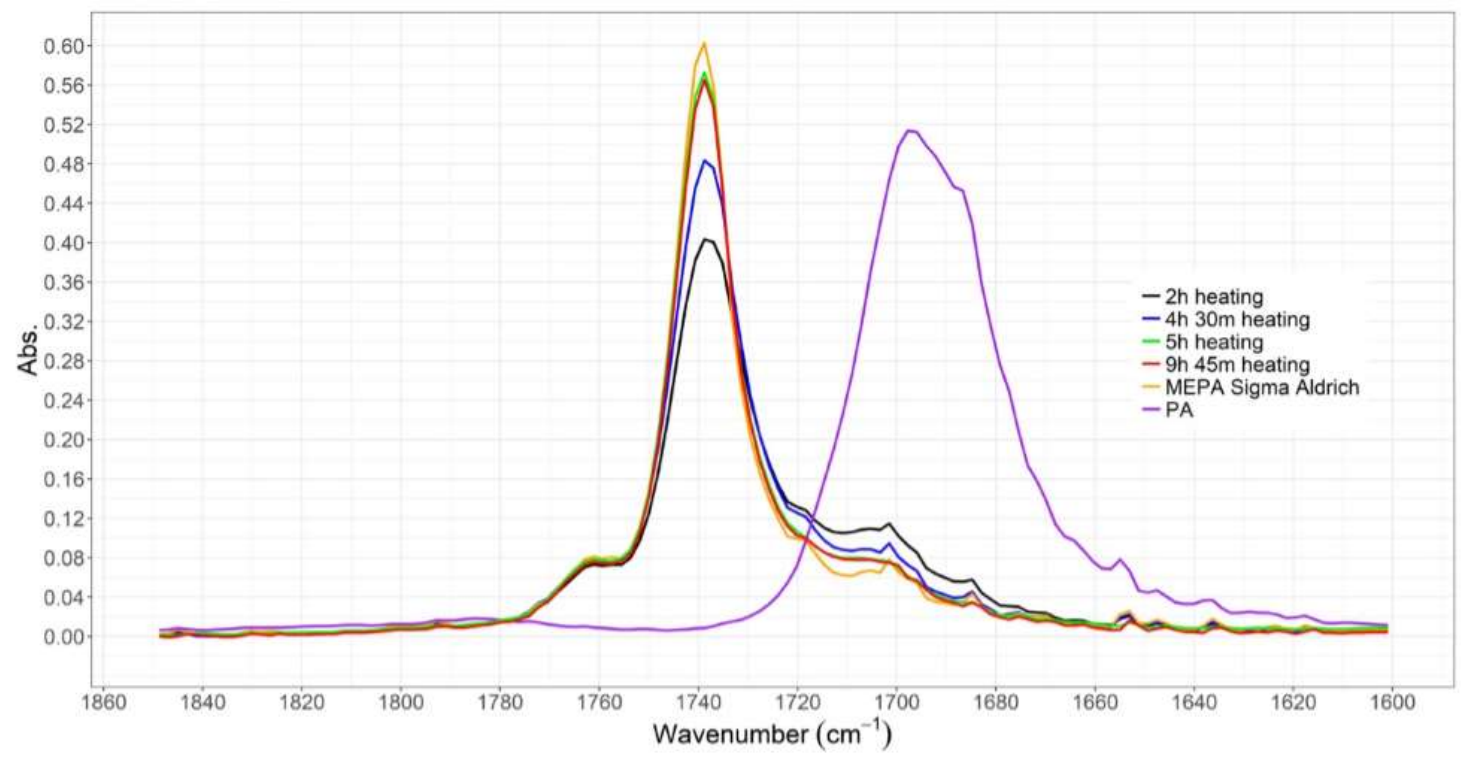

Figure 4. Investigation on the influence of heating time on the ester formation. PA impurities are seen decreasing and ester yield is increased for increased heating time, with a "plateau" reached after $5 \mathrm{~h}$ heating time.

\subsubsection{GC-MS and NMR Analysis}

In order to confirm the ester structures and the degree of purity observed in the ATR-IR for MEPA produced with 5:1 excess of $\mathrm{MeOH}$ and $5 \mathrm{~h}$ heating time, GC-MS and NMR spectra were recorded for the commercial MEPA from Sigma Aldrich and the self-produced MEPA, and compared.

Regarding GC, both commercial MEPA and PA were analyzed, and retention times of $13.880 \mathrm{~min}$ and $14.226 \mathrm{~min}$, respectively, were observed, confirming that PA impurities would be visible and the peak well separated in the self-produced MEPA chromatogram. This would allow for identification of residual unreacted acid and impurities. Afterwards, MEPA produced in the laboratory with $5 \mathrm{~h}$ heating and 5:1 excess of $\mathrm{MeOH}$ was analyzed on the same column, and the resulting chromatogram showed that the Ester produced had a retention time of $13.883 \mathrm{~min}$ as expected and purity estimated around $98 \%$.

Following GC characterization, a mass spectra of the self-produced MEPA was registered to further confirm the molecular structure (Figure 5). The peak from the molecular ion was observed at $270.2 \mathrm{~m} / \mathrm{z}$ with high abundance, as reported in literature for linear long-chained alkane systems [24]. From there, the cleavage of the methanol group was visible from the peak at $239 \mathrm{~m} / z$, corresponding to a loss of 31 of the methyl molecule $(15 \mathrm{~m} / z)$ and alcohol atom $(16 \mathrm{~m} / z)$. Side resonances at 241 and 242 are thought to be due to resonance forms of the methoxy group. From $227 \mathrm{~m} / z$ to $101 \mathrm{~m} / z$ several peaks distanced $14 \mathrm{~m} / z$ each $(227,213,199,185,171,157,143,129,115,101)$ show the progressive breaking of the aliphatic chain by loss of $-\mathrm{CH}_{2}$ from the acid side. Hence, the overall structure of MEPA was confirmed. 


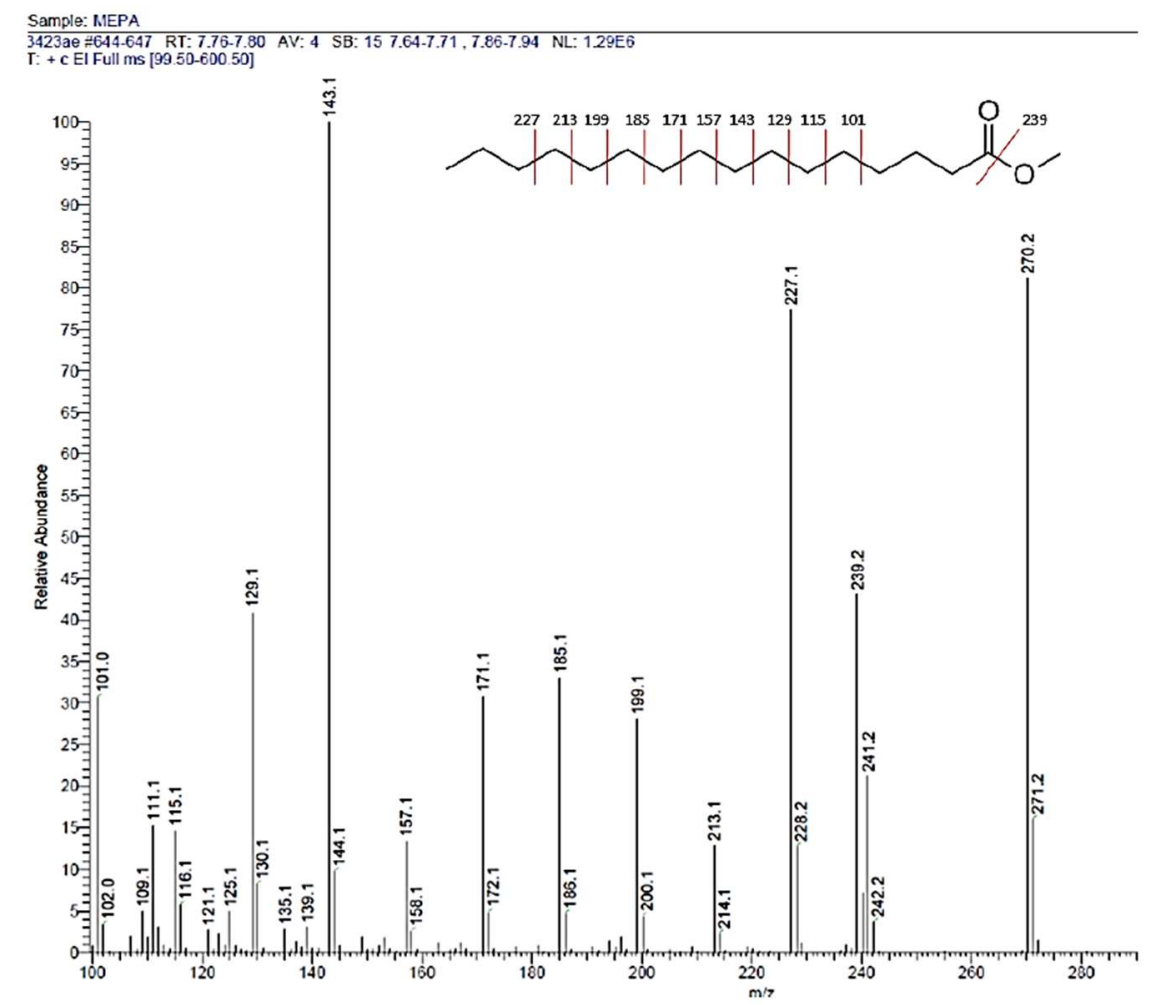

Figure 5. Mass chromatogram of MEPA produced in the laboratory. The main peaks are highlighted, and particularly the molecular ion at $270 \mathrm{~m} / z$, cleavage of methanol at $239 \mathrm{~m} / \mathrm{z}$, and progressive breaking of the aliphatic chain from $227 \mathrm{~m} / z$ to $101 \mathrm{~m} / \mathrm{z}$ with peaks distances $14 \mathrm{~m} / \mathrm{z}$ (corresponding to loss of $-\mathrm{CH}_{2}$ ).

With regards to NMR results, the spectra of self-produced MEPA with 1:5 acid:alcohol ratio and $5 \mathrm{~h}$ heating time was fully characterized, and the structure and purity confirmed. At $3.66 \mathrm{ppm}$ (a), a singlet arising from the protons of the deshielded methyl group $-\mathrm{CH}_{3}$, which resonated as a singlet due to lack of neighbouring protons, was visible. The normalized area of the peak was assigned a value of 3 to correctly calculate the amount of protons in the spectra recorded. At 2.28-2.32 ppm (b), a triplet with area 2 from the $-\mathrm{CH}_{2}$ in $\alpha$-position to the carbonyl, and a multiplet between 1.58-1.65 ppm (c) with area 2 from the $-\mathrm{CH}_{2}$ in $\beta$-position to the carbonyl was seen. The $-\mathrm{CH}_{2}$ in $\alpha$-position resonated as a triplet due to proximity with the two protons from the the $-\mathrm{CH}_{2}$ in $\beta$-position, and appeared to be more de-shielded due to the neighboring carbonyl group. An intense peak corresponding to 24 hydrogen atoms resonating together was observed around $1.26 \mathrm{ppm}(\mathrm{d})$, and was assigned to the long aliphatic chain from the fatty acid. Lastly, the $-\mathrm{CH}_{3}$ group at the end of the aliphatic chain appeared as a triplet with integrated area of 3 at $0.86-0.90 \mathrm{ppm}$ (e) due to strong shielding effect and distance from the carbonyl group and electro-withdrawing elements. By summing the integrated areas values of the peaks assigned, a total of 34 hydrogens were obtained, which matched the elemental composition $\mathrm{C}_{17} \mathrm{H}_{34} \mathrm{O}_{2}$ of MEPA (Figure 6). No impurities were observed, thus confirming the results obtained from GC-MS spectral data. Therefore, it could be concluded that commercial MEPA had been successfully replicated in the laboratory with high purity, and new esters could be produced through the Fischer esterification procedure reported above. 


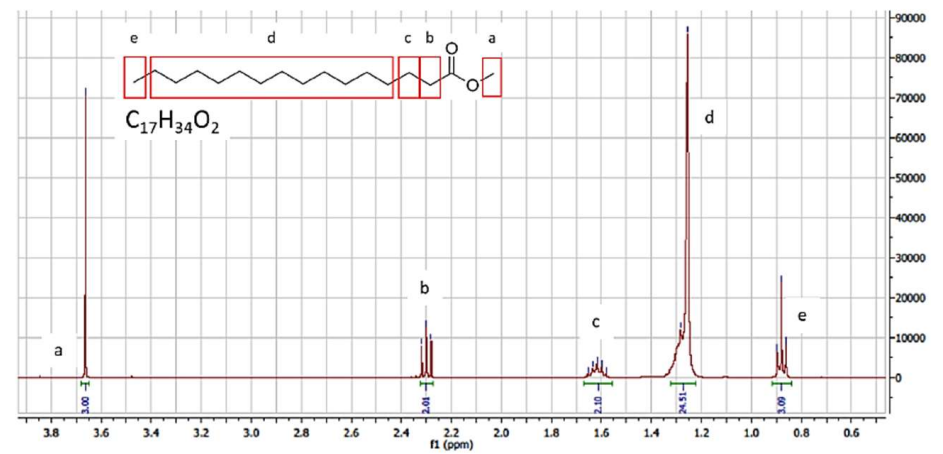

Figure 6. NMR spectra of MEPA produced in the laboratory. No impurities were detected, thus confirming GC-MS results of purity over $98 \%$. The main peaks have been assigned, in particular: the singlet at $3.66 \mathrm{ppm}$ from $-\mathrm{CH}_{3}$, the triplet from $\alpha-\mathrm{CH}_{2}$ and multiplet from $\beta-\mathrm{CH}_{2}$ at $2.28-2.32$ and $1.58-1.65 \mathrm{ppm}$, respectively, the aliphatic chain at $1.26 \mathrm{ppm}$ and finally the shielded $-\mathrm{CH}_{3}$ triplet at $0.86-0.90 \mathrm{ppm}$. The green lines indicate the integral areas, while the normalized values are indicated in blue.

\subsubsection{DSC and TGA Analysis}

Following structural and purity analysis, thermal characterization was performed by TGA and DSC to determine thermal stability (thermal degradation, cycling), melting and crystallization points $\mathrm{T}_{\mathrm{m}}$ and $\mathrm{T}_{\mathrm{c}}$, degree of supercooling and enthalpy of fusion $\triangle \mathrm{H}$ of commercial and self-produced MEPA. Commercial MEPA presented an average onset $\mathrm{T}_{\mathrm{m}}$ of $28.2^{\circ} \mathrm{C} \pm 0.2{ }^{\circ} \mathrm{C}$, and $\mathrm{T}_{\mathrm{c}}$ of $25.3^{\circ} \mathrm{C} \pm 0.1{ }^{\circ} \mathrm{C}$ in accordance to what was stated by the provider, and a supercooling of $2.9^{\circ} \mathrm{C}$ for $10^{\circ} \mathrm{C} / \mathrm{min}$ heating rate. The melting and crystallization peaks were calculated by the STAR ${ }^{\mathrm{e}}$ software through the tangent method, and the enthalpies were obtained by integration of the corresponding peak. The standard deviations were calculated from the results of the cycling tests and repetitions. For determination of phase change temperatures, onset temperatures are reported, and supercooling is calculated as the difference between onset melting temperature and onset crystallization temperature, unless stated otherwise. A high $\Delta \mathrm{H}$ of $204 \mathrm{~J} / \mathrm{g} \pm 2 \mathrm{~J} / \mathrm{g}$ was observed for commercial MEPA, indicating its suitability as PCM for LHS applications. As can be seen from Figure 7, synthesized MEPA presents phase change temperatures in accordance with the commercial sample with melting temperature of $26.3^{\circ} \mathrm{C} \pm 0.0^{\circ} \mathrm{C}$ and crystallization temperature of $24.2^{\circ} \mathrm{C} \pm 0.2{ }^{\circ} \mathrm{C}$, same degree of supercooling and stability over three heating/cooling cycles. The enthalpy of fusion observed from integration of the corresponding peak amounted to $201 \pm 1 \mathrm{~J} / \mathrm{g}$, indicating a high degree of purity in the MEPA produced, thus confirming once again the results previously reported.

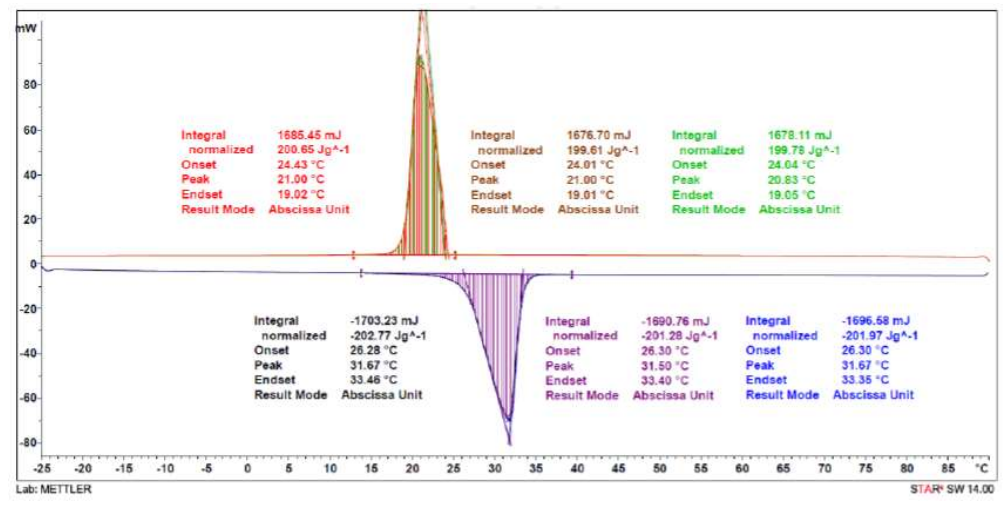

Figure 7. DSC analysis of MEPA produced in the laboratory for comparison with commercial sample. The results found of $\mathrm{T}_{\mathrm{m}}$ of $26.3^{\circ} \mathrm{C} \pm 0.0^{\circ} \mathrm{C}$ and $\mathrm{T}_{\mathrm{c}}$ of $24.2^{\circ} \mathrm{C} \pm 0.2^{\circ} \mathrm{C}$ and $\Delta \mathrm{H}$ of $201 \pm 1 \mathrm{~J} / \mathrm{g}$ are in accordance with the values expected. This indicates a high degree of purity for the sample produced, and its suitability as PCM. The STAR ${ }^{\mathrm{e}}$ Software version (14.00) is reported on the bottom right. 
Concerning TGA analysis, no residuals of methanol were observed in the sample (boiling point $64.7^{\circ} \mathrm{C}$ ), and degradation of the produced sample was complete by $240^{\circ} \mathrm{C}$ in accordance with what was registered for commercial MEPA. The starting temperature of degradation varied between 100 and $110{ }^{\circ} \mathrm{C}$ for laboratory samples, while it was around $150{ }^{\circ} \mathrm{C}$ for commercial MEPA (Figure 8). The mass loss before $150{ }^{\circ} \mathrm{C}$ was less than $5 \%$ for all laboratory MEPA samples, and the remaining $95 \%$ was lost in the range between $150-240{ }^{\circ} \mathrm{C}$ as for commercial MEPA. Therefore, it could be concluded that no significant differences in the thermal stability between the self-produced sample and commercial one existed.

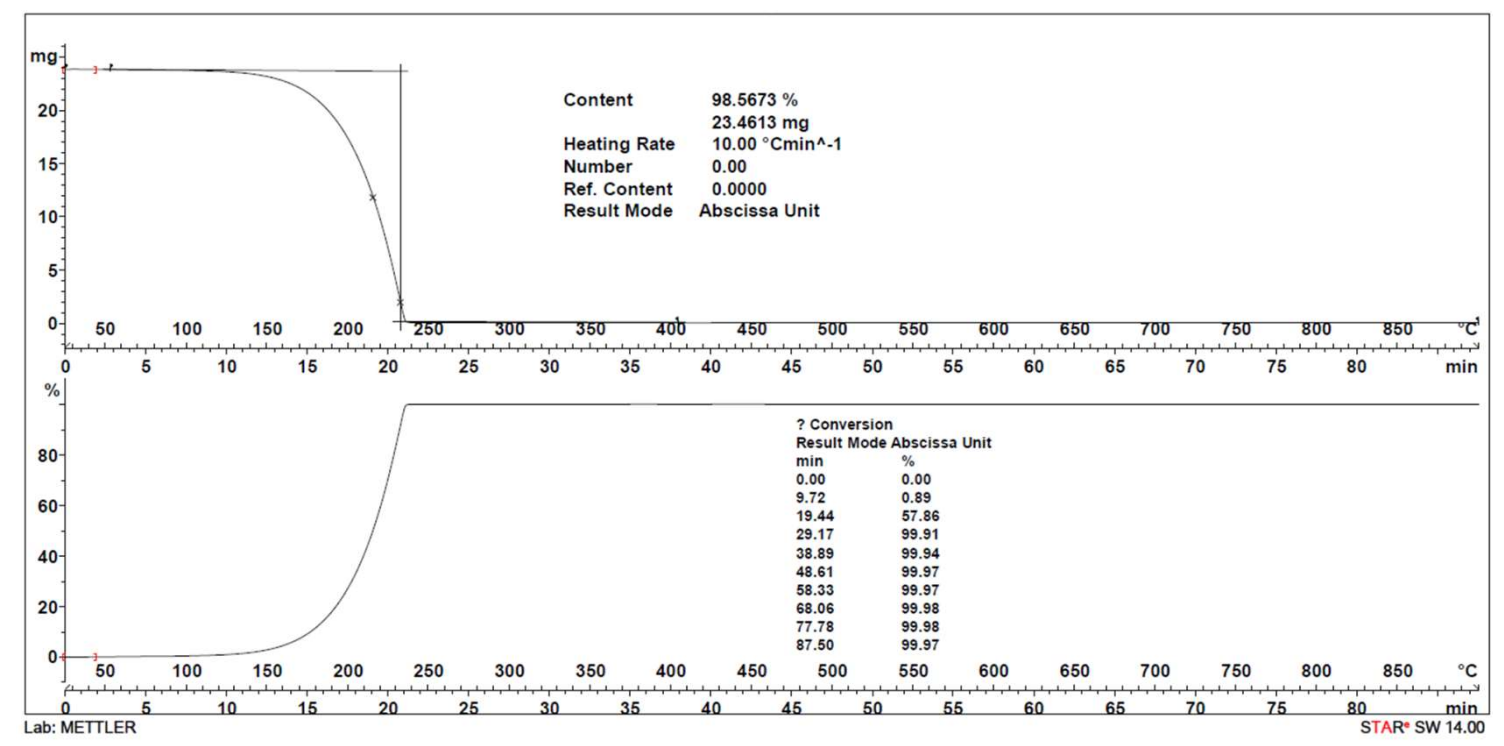

Figure 8. TGA graph of mass loss for MEPA produced in the laboratory. No significant differences with commercial MEPA were observed, as both samples registered a mass loss $\leq 5 \%$ before $150{ }^{\circ} \mathrm{C}$, and the remaining mass was lost in between the range $150{ }^{\circ} \mathrm{C}-240^{\circ} \mathrm{C}$ as expected.

\subsection{Synthesis of Methyl and Decyl Esters}

Following the optimization of the synthesis procedure, esters derived from fatty carboxylic acids coupled with $\mathrm{MeOH}$ and fatty alcohol 1-decanol were produced, as reported previously. After confirming an acceptable degree of purity $(\geq 89 \%)$, the thermal properties of the different esters were determined and subsequently analyzed and compared, in order to identify possible trends between chemical structure and thermal behavior, and to gain a broader overview of the melting points of different esters.

Concerning ATR-IR characterization, the appearance of the ester characteristic peak at $1735 \mathrm{~cm}^{-1}$, the progressive disappearance of the broad alcohol peak at $3100-3600 \mathrm{~cm}^{-1}$, and of the acid at $1705 \mathrm{~cm}^{-1}$ over time proved the efficiency of the reaction and the formation of the desired product. For all 1-decanol esters, however, a ratio of about 2:1 between the ester peak and the acid peak, respectively, was observed after drying with Rotavapor. This, together with the presence of a peak in the alcohol region, proved that not all reagents had been consumed during the reaction time. Therefore, crystallization in $\mathrm{MeOH}$ was performed until there was no visible residual alcohol peak and acid peak in the final spectra. Figure 9 shows the difference between unpurified decyl palmitate (DEPA) and DEPA crystallized twice in $\mathrm{MeOH}$ with a ratio of 1:10 for DEPA:MeOH. Generally, as reported previously, one or two crystallizations were sufficient to obtain degrees of purity over $89 \%$. 


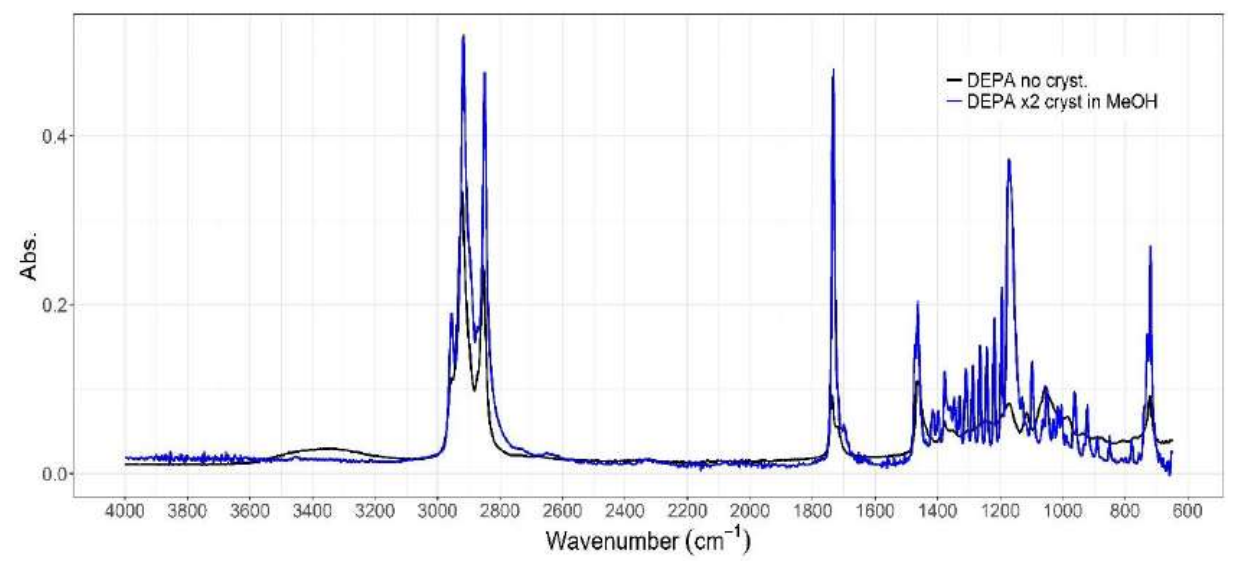

Figure 9. ATR-IR spectra of DEPA without purification and with two crystallization in $\mathrm{MeOH}$ purifications. A strong increase in the ester peak at $1735 \mathrm{~cm}^{-1}$ for ester purified twice can be observed, together with the disappearance of the residual Alcohol broad peak at $3100-3600 \mathrm{~cm}^{-1}$, which verifies the degree of purity of the ester produced and its suitability for further studies.

A clear gain in the ester band was achieved, confirming the efficacy of the purification process. However, besides purity control and synthesis control, the IR could not confirm the true identity of the esters created since no clear differences were visible in terms of the ester peak and alkane chain peaks at 2920 and $2850 \mathrm{~cm}^{-1}$. Therefore, the structure of the produced esters had to be recognized through NMR and GC-MS analysis.

The mass spectra recorded for methyl esters showed the same peaks reported for MEPA, confirming the cleavage of a methyl group with peak at $239 \mathrm{~m} / \mathrm{z}$. Esters derived from different fatty acids could be recognized by the longer or shorter fragmentation of the alkane chain by progressive loss of $-\mathrm{CH}_{2}(14 \mathrm{~m} / z)$ and by the molecular ion. On the other hand, spectra for decyl esters showed a different fragmentation pattern, especially regarding the cleavage of the alcohol chain. For instance, for DEPA (molecular peak at $396 \mathrm{~m} / z$ ), a strong signal was recorded due to the loss of the decyl alkane chain (loss of $141 \mathrm{~m} / z$, peak at $255 \mathrm{~m} / z$ ), thus forming a carboxylate group. The decyl aliphatic chain is then thought to form a decene through resonance to give the observed mass loss of $139 \mathrm{~m} / \mathrm{z}$ at corresponding peak $257 \mathrm{~m} / \mathrm{z}$. The alcohol cleavage with loss of 1-decanol (loss of $157 \mathrm{~m} / \mathrm{z}$ ) was observed at $239 \mathrm{~m} / z$, which confirms that the ester analysed was indeed a decyl ester. Additionally, the usual progressive fragmentation of the alkyl chain from the acid side is observed through steps of $14 \mathrm{~m} / \mathrm{z}$ loss each.

Similarly, the structures of the different esters could be easily identified through ${ }^{1} \mathrm{H}$ NMR analysis, as well as detection and quantification of impurities from residual alcohol or acid (Figure 10). All the ${ }^{1} \mathrm{H}$ NMR spectra of methyl esters showed a high degree of purity and no residual alcohol, therefore their purity was estimated at $\geq 98 \%$. The same main peaks as the ones observed in the spectra of replicated MEPA were observed, namely the singlet at $3.66 \mathrm{ppm}$ from the deshielded methyl group $-\mathrm{CH}_{3}$ directly attached to the carbonyl group, the triplet at 2.28-2.32 ppm from the $-\mathrm{CH}_{2}$ in $\alpha$-position to the carbonyl, the multiplet from the $-\mathrm{CH}_{2}$ in $\beta$-position at 1.58-1.65 ppm, the peak from the alkane chain around $1.26 \mathrm{ppm}$ and the triplet at $0.86-0.90 \mathrm{ppm}$ from the shielded $-\mathrm{CH}_{3}$ group at the end of the aliphatic chain. On the other hand, some variances in the spectra for decyl esters allowed differentiation between the diverse groups of esters. Here, a triplet with integral value of 2 instead of a singlet appeared at 4.05-4.07 ppm (a) from the $-\mathrm{CH}_{2}$ in $\alpha$-position to the oxygen of the ester group. This is due to the fact that in 1-decanol, unlike in methanol, the aliphatic chain continues, therefore the $-\mathrm{CH}_{2}$ in $\alpha$-position feels the influence of the neighboring $-\mathrm{CH}_{2}$. The triplet at 2.28-2.32 ppm (c) from the $-\mathrm{CH}_{2}$ in $\alpha$-position to the carbonyl group remained the same, while the multiplet at $1.58-1.65 \mathrm{ppm}$ (d) from the $-\mathrm{CH}_{2}$ groups in $\beta$-position had an integral equal to 4 hydrogens instead of 2 due to the presence of the additional $-\mathrm{CH}_{2}$ in $\beta$-position to the oxygen from the alcohol side. Similarly, the peak 
from the alkane chain at $1.26 \mathrm{ppm}$ (e) had an integral value of about 38 hydrogens, and the triplet at 0.86-0.90 ppm (f) corresponded to the 6 hydrogens from the shielded $-\mathrm{CH}_{3}$ at the end of the aliphatic chains from the acid and the alcohol sides. Small alcohol impurities, when present, were visible in the form of a triplet at 3.62-3.66 ppm (b) from the $-\mathrm{CH}_{2}$ in $\alpha$-position to the hydroxy group of the free alcohol molecules.

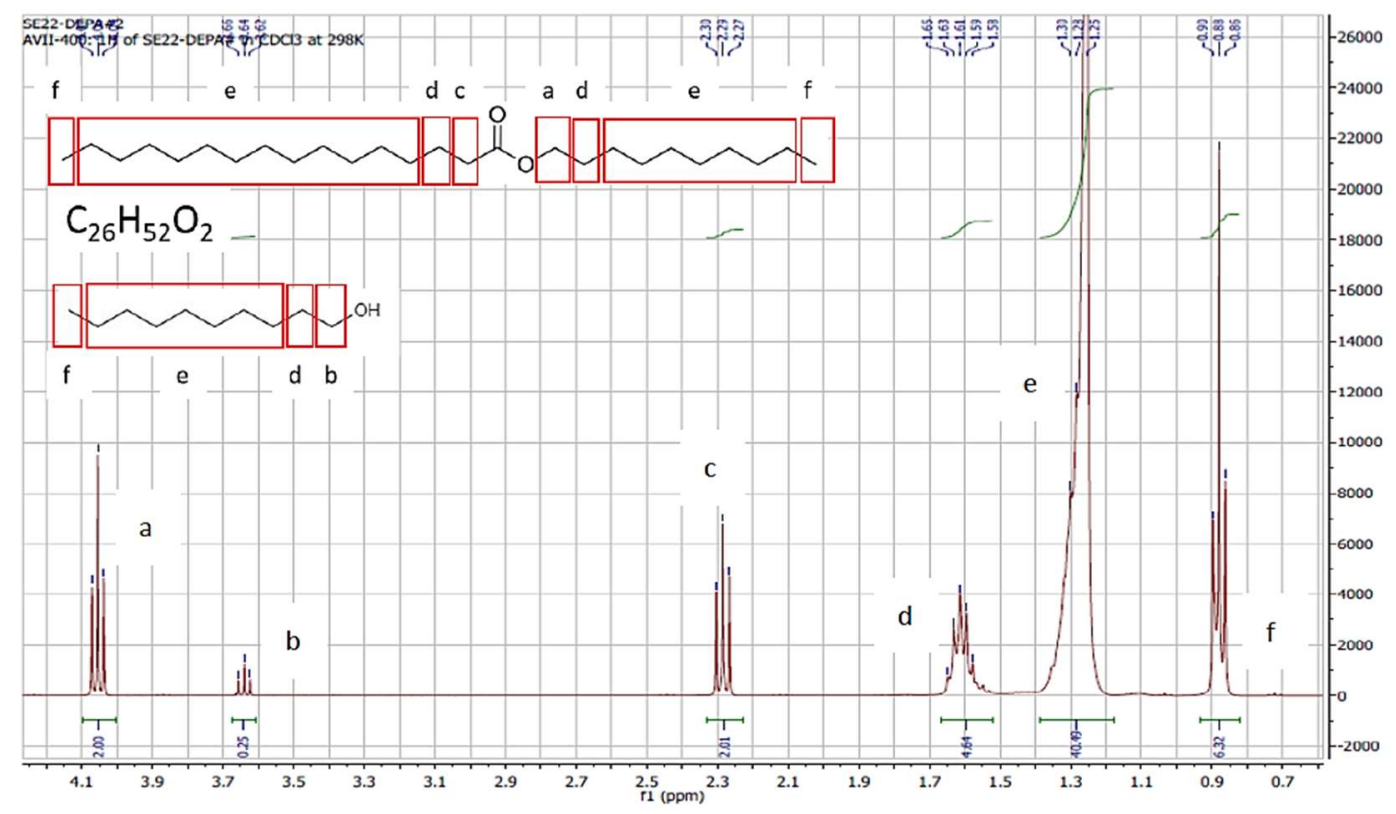

Figure 10. ${ }^{1} \mathrm{H}$ NMR spectra of $89 \%$ pure DEPA. Some differences arise compared to the spectra of methyl esters, and in particular: the triplet instead of singlet at 4.05-4.07 ppm (a) from $-\mathrm{CH}_{2}$ in $\alpha$ to the oxygen, the integral values of the peaks at $2.27-2.29 \mathrm{ppm}$ (c) from $-\mathrm{CH}_{2}$ in $\alpha$ to the carbonyl, at 1.58-1.65 ppm (d) from $-\mathrm{CH}_{2}$ in $\beta$ to the carbonyl, at $1.26 \mathrm{ppm}$ (e) from the aliphatic chain of both the alcohol and the acid, and at $0.86-0.90$ ppm (f) from shielded $-\mathrm{CH}_{3}$ groups at the end of the aliphatic chains from both the alcohol and acid side. Impurities from residual alcohol can be observed and quantified through the integral value of the triplet at 3.62-3.66 ppm (b) assigned to the $-\mathrm{CH}_{2}$ in $\alpha$ to the hydroxyl groups in the free unreacted alcohol molecules. Similarly as for previous pictures, the green lines indicate the integral areas, while the normalized values are indicated in blue.

The ratio between its integral value and the one from the ester signal at 4.05-4.07 ppm allowed to quantify the degree of purity of the sample. As mentioned previously, in the absence of any additional peaks from unreacted reagents, the purity was estimated to be $\geq 98 \%$, like in the case of methyl esters.

Impurities still present in the decyl esters could also be observed through DSC analysis. In the presence of residual alcohol, a second broad peak appeared between $2-10{ }^{\circ} \mathrm{C}\left(\mathrm{T}_{\mathrm{m}}\right.$ of 1-Decanol: $\left.6.4^{\circ} \mathrm{C}\right)$, and lower $\Delta \mathrm{H}$ of about $150-160 \mathrm{~J} / \mathrm{g}$ were registered. Upon further crystallizations and purifications though, such peak decreased until it was barely visible over the baseline noise of the instrument, and $\Delta \mathrm{H}$ for the ester peak increased again to values over $190 \mathrm{~J} / \mathrm{g}$.

In general, the results obtained concerning thermal properties of synthesized esters are summarized in Table 1. As mentioned beforehand, the esters names have been abbreviated as follows: methyl myristate (MEMY, C1-14), decy myristate (DEMY, C10-C14), methyl palmitate (MEPA, C1-C16), decyl palmitate (DEPA, C10-C16), methyl stearate (MESA, C1-C18), decyl stearate (DESA, C10-C18), methyl behenate (MEBE, C1-C22), decyl behenate (DEBE, C10-C22). 
Table 1. Summary of thermal properties of the ester produced. The colors indicate the temperature gradient from the lowest values (blue) to the highest (red). A trend between degradation temperatures and molecular structure is observed, with a progressive growth of the thermal stability together with carbon chain length. This is supposedly due to longer chains' ability to create more compact crystal packing structures, thus stronger intermolecular forces. No clear correlation between $\Delta \mathrm{H}(\mathrm{J} / \mathrm{g}$ ) and the structure can be deduced, however all $\Delta \mathrm{H}(\mathrm{J} / \mathrm{g})$ values registered were over $190 \mathrm{~J} / \mathrm{g}$, confirming the fatty acid esters' suitability as PCM. An increase in molar $\Delta \mathrm{H}(\mathrm{KJ} / \mathrm{mol})$ is observed for increasing molecular weights.

\begin{tabular}{|c|c|c|c|c|c|c|c|c|c|c|c|}
\hline & Structure & $\begin{array}{l}\text { Carbon } \\
\text { Number }\end{array}$ & $\begin{array}{l}\text { MW } \\
(\mathrm{g} / \mathrm{mol})\end{array}$ & Purity & $\mathrm{T}_{\mathrm{c}}$ (onset, ${ }^{\circ} \mathrm{C}$ ) & $\mathrm{T}_{\mathrm{m}}$ (onset, $\left.{ }^{\circ} \mathrm{C}\right)$ & $\begin{array}{c}\text { Supercooling } \\
\left({ }^{\circ} \mathrm{C}\right)\end{array}$ & $\Delta \mathrm{H}(\mathrm{J} / \mathrm{g})$ & $\underset{(\mathrm{KJ} / \mathrm{mol})}{\Delta \mathrm{H}}$ & $\begin{array}{l}\mathrm{T}_{\text {degradation }} \\
\left(\text { (Start, }{ }^{\circ} \mathrm{C}\right)\end{array}$ & $\begin{array}{l}\mathrm{T}_{\text {degradation }} \\
\text { (End, }{ }^{\circ} \mathrm{C} \text { ) }\end{array}$ \\
\hline MEMY (C1-C14) & $\mathrm{C}_{15} \mathrm{H}_{30} \mathrm{O}_{2}$ & 15 & 242.4 & $98 \%$ & $13.5 \pm 1.2$ & $14.7 \pm 1.9$ & 1.2 & $190 \pm 2$ & 46.1 & $87 \pm 12$ & $233 \pm 12$ \\
\hline MEPA (C1-C16) & $\mathrm{C}_{17} \mathrm{H}_{34} \mathrm{O}_{2}$ & 17 & 270.5 & $98 \%$ & $24.2 \pm 0.2$ & $26.3 \pm 0.0$ & 2.1 & $201 \pm 1$ & 54.4 & $119 \pm 10$ & $272 \pm 4$ \\
\hline MESA (C1-C18) & $\mathrm{C}_{19} \mathrm{H}_{38} \mathrm{O}_{2}$ & 19 & 298.5 & $98 \%$ & $31.9 \pm 1.1$ & $35.6 \pm 1.0$ & 3.7 & $204 \pm 1$ & 60.9 & $117 \pm 7$ & $287 \pm 6$ \\
\hline MEBE (C1-C22) & $\mathrm{C}_{23} \mathrm{H}_{46} \mathrm{O}_{2}$ & 23 & 354.6 & $98 \%$ & $41.5 \pm 1.0$ & $47.9 \pm 0.7$ & 6.4 & $200 \pm 5$ & 70.9 & $155 \pm 7$ & $305 \pm 20$ \\
\hline DEMY (C10-C14) & $\mathrm{C}_{24} \mathrm{H}_{48} \mathrm{O}_{2}$ & 24 & 368.7 & $98 \%$ & $22.9 \pm 0.2$ & $25.2 \pm 0.4$ & 2.3 & $196 \pm 3$ & 72.3 & $130 \pm 5$ & $318 \pm 11$ \\
\hline DEPA (C10-C16) & $\mathrm{C}_{26} \mathrm{H}_{52} \mathrm{O}_{2}$ & 26 & 396.7 & $89 \%$ & $28.9 \pm 1.2$ & $29.0 \pm 1.9$ & 0.1 & $193 \pm 6$ & 76.6 & $145 \pm 7$ & $310 \pm 14$ \\
\hline DESA (C10-C18) & $\mathrm{C}_{28} \mathrm{H}_{56} \mathrm{O}_{2}$ & 28 & 424.8 & $98 \%$ & $33.8 \pm 1.3$ & $36.2 \pm 0.8$ & 2.4 & $192 \pm 6$ & 81.6 & $205 \pm 20$ & $350 \pm 14$ \\
\hline DEBE (C10-C22) & $\mathrm{C}_{32} \mathrm{H}_{64} \mathrm{O}_{2}$ & 32 & 480.9 & $95 \%$ & $44.7 \pm 0.6$ & $44.8 \pm 0.7$ & 0.1 & $193 \pm 9$ & 92.8 & $200 \pm 20$ & $375 \pm 21$ \\
\hline
\end{tabular}


A trend can be observed in the degradation temperatures, with the longer chained esters being the most stable and starting to degrade at much higher temperatures compared to shorter ones. This can be explained using literature reports, with longer chain esters being able to create tighter crystal structures and therefore stronger intermolecular bonding, thus requiring higher temperature to break the bonds [15-18]. A similar behavior would be expected regarding melting temperatures $T_{m}$. However, as can be clearly observed, MEBE was the ester showing higher melting temperature and not DEBE, as would have been expected.

Upon reversing the order of the esters shown above, a trend is revealed between molecular structure and melting points (Table 2). The melting points are seen increasing based on both the fatty acid carbon length and the alcohol length, but those from decyl esters follow a parallel trend to methyl ester, and do not show the same behavior (Figure 11). What reported above is found to be true for both $T_{m}$ and $T_{c}$ for all samples. This could be due to the odd-even numbered effect explained by Noël et al. [17] and Yang et al. [18], according to which different but parallel trends can be observed between odd-numbered and even-numbered carbon chain series. In addition, the length of the fatty acid carbon chain seems to have a higher impact on the resulting phase transition temperature of the ester, compared to the alcohol.

Table 2. Rearrangement of the previous table to show the dependency of phase transition temperature on fatty ester type and carbon chain length. As for Table 1, the colors indicate the temperature gradient from the lowest temperature values (blue) to the highest (red).

\begin{tabular}{cccc}
\hline & Carbon Number & $\mathbf{T}_{\mathbf{c}}\left(\right.$ Onset $\left.^{\circ}{ }^{\circ} \mathbf{C}\right)$ & $\mathbf{T}_{\mathbf{m}}$ (Onset, $\left.{ }^{\circ} \mathbf{C}\right)$ \\
\hline MEMY $($ C1-C14) & 15 & $13.5 \pm 1.2$ & $14.7 \pm 1.9$ \\
DEMY (C10-C14) & 24 & $22.9 \pm 0.2$ & $25.2 \pm 0.4$ \\
MEPA (C1-C16) & 17 & $24.2 \pm 0.2$ & $26.3 \pm 0.0$ \\
DEPA (C10-C16) & 26 & $28.9 \pm 1.2$ & $29.0 \pm 1.9$ \\
MESA (C1-C18) & 19 & $31.9 \pm 1.1$ & $35.6 \pm 1.0$ \\
DESA (C10-C18) & 28 & $33.8 \pm 1.3$ & $36.2 \pm 0.8$ \\
MEBE (C1-C22) & 23 & $41.5 \pm 1.0$ & $47.9 \pm 0.7$ \\
DEBE (C10-C22) & 32 & $44.7 \pm 0.6$ & $44.8 \pm 0.7$ \\
\hline
\end{tabular}

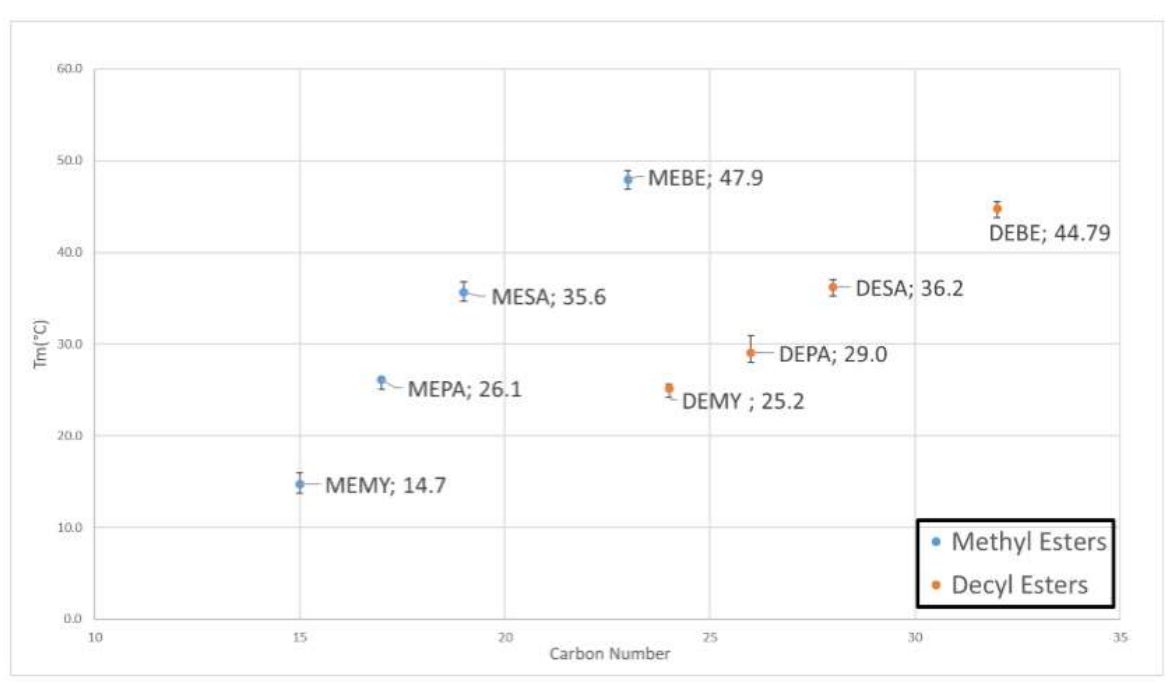

Figure 11. Methyl esters and decyl esters both show a correlation between $T_{m}$ and $T_{c}$ and carbon chain length, but following different behaviors; this is believed to be due to the odd-even effect [17-20,22,23]. The acid carbon chain length seems to have higher impact than the alcohol.

The molar enthalpies of fusion $(\Delta \mathrm{H}$ in $\mathrm{KJ} / \mathrm{moL})$ could be seen increasing with increasing chain length and molecular weight; however, no clear trends could be observed for even and odd-numbered 
esters as for $\mathrm{T}_{\mathrm{m}}$. Nevertheless, all values measured were above $190 \mathrm{~J} / \mathrm{g}$ with uncertainties around $1.5 \%$, confirming the suitability of fatty esters as PCM. All of the samples proved to be stable to short cycles (three times), with variations lower than $0.5^{\circ} \mathrm{C}$. Additionally, supercooling lower than $7{ }^{\circ} \mathrm{C}$ were observed in all cases at a rate of $10^{\circ} \mathrm{C} / \mathrm{min}$.

\section{Conclusions}

In conclusion, fatty esters from methanol and 1-decanol and fatty acids of different carbon chain length (myristic acid, palmitic acid, stearic acid, behenic acid) to be used as possible PCM were successfully synthesized through Fischer esterification with purities over $89 \%$. While methyl esters of myristic, palmitic and stearic acid have been synthesized before and their thermal properties partially investigated, to the best of the author's knowledge, a clear lack in experimental thermal data exists in regards of methyl behenate and all decyl esters produced. The synthetic procedure was validated through comparison of properties of the self-produced methyl palmitate with the commercial homologue purchased. While simple drying with rotary evaporation was sufficient to purify the final methyl esters, all decyl esters had to be further purified through one or more consequent crystallizations in methanol. ATR-IR proved to be a valid technique for identification of residual unreacted acid or alcohol in a qualitative manner; however, it did not allow for identification of different esters. On the other hand, NMR and GC-MS analysis allowed for correct identification of structures and compound identity. Additionally, eventual residual impurities could be successfully detected and quantified through both methods. Identification of residual impurities was possible also through DSC analysis, where side peaks could be observed in case of impurities, together with lower $\Delta \mathrm{H}$. The phase change temperatures of the esters ranged between $14^{\circ} \mathrm{C}$ and $45^{\circ} \mathrm{C}$ circa. As reported by Du et al. [25], PCM in the range between $5{ }^{\circ} \mathrm{C}$ and $40^{\circ} \mathrm{C}$ appear to be interesting for low-medium temperature applications, such as free cooling $\left(19-24{ }^{\circ} \mathrm{C}\right.$ ), evaporative and radiative cooling systems (around $18{ }^{\circ} \mathrm{C}$ ), solar absorption chillers $\left(29^{\circ} \mathrm{C}\right)$, and passive heating and cooling of buildings $\left(19-29^{\circ} \mathrm{C}\right)$. Preliminary works conducted on such setups with different PCM (salt hydrates, paraffins) showed promising results, with high cost saving and decrease in energy consumption (25-30\%). The esters produced proved to be interesting PCM candidates thanks to $\Delta \mathrm{H}$ over $190 \mathrm{~J} / \mathrm{g}$ for $10{ }^{\circ} \mathrm{C} / \mathrm{min}$ heating rates. Additionally, the DSC indicates rather moderate supercooling rates for all samples. A trend could be observed correlating both degradation temperatures and phase transition temperatures to the chemical structure of the molecules. In the first case, a higher thermal stability was observed for longer carbon chains, confirming the tendency of longer molecules to form more tightly packed structures and stronger intermolecular bonds. On 2424the other hand, an increase in the melting temperatures with increasing carbon chain length was observed for both methyl esters and decyl esters, but with parallel trends and a higher influence from the fatty acid carbon length compared to the alcohol. This is attributed to odd-even numbered carbon chain length effect described in previous works $[17,18]$.

Given the lack of experimental thermal data on esters, future research on different ester classes (e.g. diesters, lactones, aromatic, benzylic esters) is planned, in order to collect further information about the thermal behavior and possible trends, and to individuate the best suitable candidates to be used as PCM for different scopes and applications.

Author Contributions: All authors listed conceived and designed the project and contributed to experiments' development and in reviewing the paper; A.S., J.W, and L.J.F acquired the funding; R.R. and N.L. performed the experiments; R.R., N.L., O.F. and A.S. analyzed the data; O.F. contributed reagents, materials and analysis tools; R.R. wrote the paper.

Funding: This research was funded by Swiss National Science Foundation (SNSF, project number PZENP2_173636).

Acknowledgments: This work was developed within the framework of the project DENSE “Direct-contact ENergy StoragE" funded by the Swiss National Science Foundation (SNSF, project number PZENP2_173636) with the support of the Swiss Competence Center for Energy Research Storage of Heat and Electricity (SCCER). The authors wish to thank the University of Zürich (UZH, Zürich, Switzerland) and Fachhochschule Nordwestschweiz (FHNW, Basel, Switzerland) for the GC-MS and NMR measurements conducted.

Conflicts of Interest: The authors declare no conflict of interest. 


\section{List of Abbreviations}

$\begin{array}{ll}\text { ATR-IR } & \text { Attenuated Total Reflectance InfraRed Spectroscopy } \\ \text { BE } & \text { Behenic Acid } \\ \text { DEBE } & \text { Decyl Behenate (C10-C22) } \\ \text { DEMY } & \text { Decyl Myristate (C10-C14) } \\ \text { DEPA } & \text { Decyl Palmitate (C10-C16) } \\ \text { DESA } & \text { Decyl Stearate (C10-C18) } \\ \text { DSC } & \text { Differential Scanning Calorimetry } \\ \text { Et }_{2} \mathrm{O} & \text { Diethyl Ether } \\ \text { EtOAc } & \text { Ethyl Acetate } \\ \text { GC-MS } & \text { Gas-Chromatography coupled with Mass Spectrometry } \\ \mathrm{H}_{2} \mathrm{SO}{ }_{4} & \text { Sulfuric Acid } \\ \text { IEA } & \text { International Energy Agency } \\ \text { LHS } & \text { Latent Heat Storage } \\ \text { MEBE } & \text { Methyl Behenate (C1-C22) } \\ \text { MEMY } & \text { Methyl Myristate (C1-C14) } \\ \text { MeOH } & \text { Methanol } \\ \text { MEPA } & \text { Methyl Palmitate (C1-C16) } \\ \text { MESA } & \text { Methyl Stearate (C1-C18) } \\ \text { MY } & \text { Myristic Acid } \\ \text { Na }{ }_{2} S \text { }_{4} & \text { Sodium Sulfate } \\ \text { NMR } & \text { Nuclear Magnetic Resonance } \\ \text { PA } & \text { Palmitic Acid } \\ \text { PCM } & \text { Phase Change Material } \\ \text { SA } & \text { Stearic Acid } \\ \text { SHS } & \text { Sensible Heat Storage } \\ \mathrm{T}_{\mathrm{c}} & \text { Crystallization Temperature } \\ \text { TCS } & \text { Thermochemical Storage Material } \\ \text { TGA } & \text { Thermogravimetric Analysis } \\ \mathrm{T}_{\mathrm{m}} & \text { Melting Temperature } \\ \Delta \mathrm{H} & \text { Enthalpy of fusion } \\ & \end{array}$

\section{Appendix A}
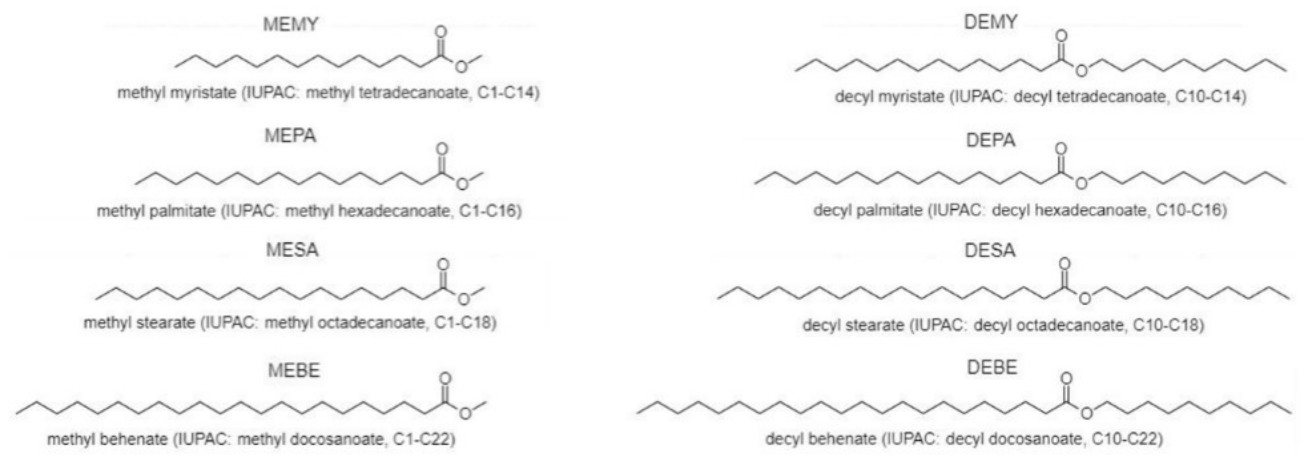

Figure A1. Structures and trivial names of esters produced, with IUPAC nomenclature and carbon length shortening in between brackets. The carbon length shortening indicates first the number of carbons in the alcohol, and subsequently the number of carbons in the carboxylic acid chain. For example, methyl myristate derives from methanol (C1) and myristic acid (C14), therefore is indicated as C1-C14. 


\section{References}

1. International Energy Agency (IEA). Key World Energy Statistics. 2017. Available online: https://www.iea. org/publications / freepublications / publication/KeyWorld2017.pdf (accessed on 19 May 2018).

2. Pielichowska, K.; Pielichowski, K. Phase change materials for thermal energy storage. Prog. Mater. Sci. 2014, 65, 67-123. [CrossRef]

3. Nkwetta, D.N.; Haghighat, F. Thermal energy storage with phase change material-A state-of-the art review. Sustain. Cities Soc. 2013, 10, 87-100. [CrossRef]

4. Sharma, A.; Tyagi, V.V.; Chen, C. Experimental study for the melting of PCM inside concentric horizontal cylindrical annuli. In Proceedings of the 6th International Conference on Thermal Energy Storage, Espoo, Finland, 15-17 August 1994; pp. 503-511.

5. Sarbu, I.; Sebarchievici, C. A Comprehensive Review of Thermal Energy Storage. Sustainability 2018, 10, 191-223. [CrossRef]

6. Mehling, H.; Cabeza, L.F. Heat and Cold Storage with PCM. An up to Date Introduction into Basics and Applications; Springer: Berlin, Germany, 2008; ISBN 978-3-540-68556-2.

7. Liu, M.; Saman, W.; Bruno, F. Review on storage materials and thermal performance enhancement techniques for high temperature phase change thermal storage systems. Renew. Sustain. Energy Rev. 2012, 16, 2118-2132. [CrossRef]

8. Abhat, A. Low Temperature Latent Heat Thermal Energy Storage: Heat Storage Materials. Sol. Energy 1983, 30, 313-332. [CrossRef]

9. Yuan, Y.; Zhang, N.; Tao, W.; Cao, X.; He, Y. Fatty Acids as phase change materials: A review. Renew. Sustain. Energy Rev. 2014, 29, 482-498. [CrossRef]

10. Cabeza, F.L.; Castell, A.; Barreneche, C.; de Gracia, A.; Fernandez, A.I. Materials used as PCM in thermal energy storage in buildings: A review. Renew. Sustain. Energy Rev. 2011, 15, 1675-1695. [CrossRef]

11. Menoufli, K.; Castell, A.; Farid, M.M.; Boer, D.; Cabeza, F.L. Life cycle assessment of experimental cubicles including PCM manufactured from natural resources (Esters): A theoretical study. Energy Convers. Manag. 2003, 44, 2277-2287. [CrossRef]

12. Stamatiou, A.; Obermeyer, M.; Fischer, L.J.; Schuetz, P.; Wortlischek, J. Investigation of unbranched, saturated, Carboxylic Esters as phase change materials. Renew. Energy 2017, 108, 401-409. [CrossRef]

13. Aydin, A.A.; Okutan, H. High-chain Fatty Acid Esters of myristic Alcohol with even carbon number: Novel organic phase change materials for thermal energy storage-1. Sol. Energy Mater. Sol. Cells 2011, 95, 2752-2762. [CrossRef]

14. Aydin, A.A. DiEsters of high-chain diCarboxylic Acids with 1-tetradecanol as novel organic phase change materials for thermal energy storage. Sol. Energy Mater. Sol. Cells 2012, 104, 102-108. [CrossRef]

15. Carnelley, T. Chemical Symmetry, or the Influence of Atomic Arrangement on the Physical Properties of Compounds. Lond. Edinb. Dublin Philos. Mag. J. Sci. 1882, 12, 112-130. [CrossRef]

16. Boese, R.; Kirchner, M.T.; Dunitz, J.D.; Filippin, G.; Gavezzotti, A. Solid-State Behaviour of the Dichlorobenzenes: Actual, Semi-Virtual and Virtual Christallography. Helv. Chim. Acta 2001, 84, 1561-1577. [CrossRef]

17. Noël, J.A.; Samer, K.; White, M.A. Molecular Structure and Melting: Implications for Phase Change Materials. Can. J. Chem. 2017, 1-8. [CrossRef]

18. Yang, K.; Cai, Z.; Jaiswal, A.; Tyagi, M.; Moore, J.S. Dynamic Odd-Even Effect in Liquid n-Alkanes near their Melting Points. Angew. Chem. Int. Ed. 2006, 55, 14090-14095. [CrossRef] [PubMed]

19. Sari, A.; Biçer, A.; Karaipekli, A. Synthesis, characterization, thermal properties of a series of stearic Acid Esters as novel solid-liquid phase change materials. Mater. Lett. 2009, 63, 1213-1216. [CrossRef]

20. Becker, H.G.O.; Berger, W.; Domschke, G.; Fanghänel, E.; Faust, J.; Fischer, M.; Gentz, F.; Gewald, K.; Gluch, R.; Mayer R Müller, K. Organikum, Organisch-Chemisches Grundpraktikum, 2nd ed.; Wiley-VCH Verlag GmbH: Weinheim, Germany, 2004; pp. 226-233. ISBN 3-527-31148-3.

21. Buddrus, J.; Schmidt, B. Grundlagen der Organischen Chemie, 5th ed.; Walter de Gruyter GmbH: München, Germany, 2015; pp. 154-196. ISBN 978-3-11-030559-3.

22. Cassel, R.B. TA Instruments Application Note. Available online: http://www.tainstruments.com/pdf/ literature/TA297.pdf (accessed on 4 May 2018). 
23. Spectra Analysis Application Note 005. Available online: http://www.spectra-analysis.com (accessed on 19 April 2018).

24. Jabbar, A.; Ali, A.; Tawab, A.; Iqbal, M. Fatty Acid Profiling of Lipid A Isolated from Indigenous Salmonella Typhi Strain by Gas Chromatography Mass Spectrometry. J. Chem. Soc. Pak. 2014, 36, 140-149.

25. Du, K.; Calautit, J.; Wang, Z.; Wu, Y.; Liu, H. A review of the applications of phase change materials in cooling, heating and power generation in different temperature ranges. Appl. Energy 2018, 220, 242-273. [CrossRef]

(c) (C) 2018 by the authors. Licensee MDPI, Basel, Switzerland. This article is an open access article distributed under the terms and conditions of the Creative Commons Attribution (CC BY) license (http:/ / creativecommons.org/licenses/by/4.0/). 